2009

\title{
Long-Term Incidence And Timing Of Intraocular Hypertension After Intravitreal Triamcinolone Acetonide Injection
}

Daniel B. Roth

Varun Verma

Tony Realini

Jonathan L. Prenner

William J. Feuer

See next page for additional authors

Follow this and additional works at: https://researchrepository.wvu.edu/faculty_publications

\section{Digital Commons Citation}

Roth, Daniel B.; Verma, Varun; Realini, Tony; Prenner, Jonathan L.; Feuer, William J.; and Fechtner, Robert D., "Long-Term Incidence And Timing Of Intraocular Hypertension After Intravitreal Triamcinolone Acetonide Injection" (2009). Faculty Scholarship. 583.

https://researchrepository.wvu.edu/faculty_publications/583 
Authors

Daniel B. Roth, Varun Verma, Tony Realini, Jonathan L. Prenner, William J. Feuer, and Robert D. Fechtner 


\section{Long-Term Incidence and Timing of Intraocular Hypertension after Intravitreal Triamcinolone Acetonide Injection}

Daniel B. Roth, MD,${ }^{1}$ Varun Verma, MD,${ }^{1}$ Tony Realini, MD ${ }^{2}$ Jonathan L. Prenner, MD ${ }^{1}$ William J. Feuer, MS, ${ }^{3}$ Robert D. Fechtner, $\mathrm{MD}^{4}$

Purpose: To describe the long-term incidence and timing of steroid-induced ocular hypertension after intravitreal triamcinolone acetonide (IVTA) therapy.

Design: Retrospective case series of 929 eyes of 841 patients.

Participants: Patients with a variety of posterior segment disorders in a single group practice.

Intervention: Pars plana injection of IVTA.

Main Outcome Measures: Intraocular pressure (IOP) and requirement for glaucoma surgery.

Results: Overall, 929 eyes received $\geq 1$ injections (mean, 1.6) of 4 mg of IVTA. During a mean follow-up period of $14 \pm 6.9$ months, the Kaplan-Meier cumulative incidences of IOP elevations $>21 \mathrm{mmHg}$ at $6,12,18$, and 24 months post-injection were $28.2 \%, 34.6 \%, 41.2 \%$, and $44.6 \%$, respectively; similarly, the incidences of eyes with IOP measurements $>25 \mathrm{mmHg}$ were $14.6 \%, 19.1 \%, 24.1 \%$, and $28.2 \%$, respectively. At the same time points, IOP-lowering medications were required by $13.0 \%, 16.9 \%, 20.7 \%$, and $24.2 \%$ of eyes, respectively. Only 3 eyes $(0.3 \%)$ required IOP-lowering surgery. Preexisting glaucoma, younger age, and a history of an IOP elevation after a previous IVTA injection were risk factors for IOP elevations after IVTA injection. The minimum and maximum follow-up were 3 weeks and 37 months. The mean rate of attrition in this study was $3 \%$ per month.

Conclusions: Elevations in IOP after IVTA injection are common. Younger patients and eyes with preexisting glaucoma or a history of a steroid response should be monitored more closely for IOP elevations after IVTA therapy.

Financial Disclosure(s): The authors have no proprietary or commercial interest in any materials discussed in this paper. Ophthalmology 2009;116:455-460 () 2009 by the American Academy of Ophthalmology.

Steroid-induced elevations of intraocular pressure (IOP) were first reported $>40$ years ago, when some eyes treated with topical dexamethasone were noted to manifest significant IOP responses. ${ }^{1-3}$ Since then, steroid-induced ocular hypertension has been observed after virtually every route of administration for corticosteroids. ${ }^{4}$ The onset of this phenomenon is variable after initiation of corticosteroid therapy, and the magnitude of the steroid response is equally variable, ranging from a rise of a few millimeters of mercury to dramatic rises of $>40 \mathrm{mmHg}$. Traditional IOPlowering therapy, including topical and oral medications, laser trabeculoplasty, ${ }^{5-7}$ and incisional surgery, have all shown efficacy in lowering steroid-induced elevations of IOP. Definitive treatment consists of discontinuation of steroid therapy, although this is not always practical or possible given the nature and severity of the underlying disease process requiring corticosteroid therapy. In addition, the route of administration may also limit the ability to discontinue therapy. In the setting of topical, oral, or parenteral administration, dosing can be discontinued upon the onset of an IOP response. Depot injections, such as those administered in the sub-Tenon's space or the intravitreal cavity, are more difficult to remove and thus pose a greater clinical challenge.

Intravitreal injection of the corticosteroid triamcinolone acetonide has been advocated for a number of posterior segment conditions, including age-related macular degeneration, ocular manifestations of diabetes including proliferative retinopathy and macular edema, retinal vein occlusions, and noninfectious posterior uveitis. ${ }^{8}$ Although the safety and efficacy profile of intravitreal triamcinolone acetonide (IVTA) in these and other ocular conditions has not been rigorously established through well-designed, randomized, clinical trials, it is clear that elevated IOP is a common and serious side effect of IVTA therapy. ${ }^{4,8}$ The management of IOP elevation after IVTA therapy is made difficult by the inability to remove the inciting agent, the significant magnitude of IOP elevation in many cases, the long duration of IOP elevation after even a single injection, and the failure of conservative management to lower IOP to a safe range in a significant minority of cases.

The purpose of this report is to describe the incidence and characteristics of IOP elevations after intravitreal administration of triamcinolone acetonide, as observed in a series of 929 eyes of 841 patients from a single practice receiving $\geq 1$ IVTA injections and followed for a mean of $>1$ year.

\section{Methods}

This retrospective review followed 929 eyes of 841 consecutive patients receiving $\geq 1$ IVTA injection for a minimum of 3 months post-injection. The study protocol was approved by the Robert 
Wood Johnson Medical School institutional review board. All injections were given between June 2001 and June 2004. The indications for IVTA therapy are given in Table 1. All intravitreal injections of triamcinolone acetonide $(4 \mathrm{mg})$ were given via sterile technique, using a sterile lid speculum and after a drop of $5 \%$ to $10 \%$ iodine-povidine solution as described previously. ${ }^{9}$ All patients were examined 1 to 7 days after each injection, and then at the discretion of the treating physician. Intraocular pressure was assessed at every visit.

Data were collected by way of a retrospective review. The data collected included diagnosis warranting IVTA therapy and dates of injections and follow-up visits. At each visit, the following data were recorded: visual acuity, IOP, and the occurrence of any adverse events.

The incidence of IOP elevation, defined at thresholds of $>21$ $\mathrm{mmHg}$ and $>25 \mathrm{mmHg}$, at $6,12,18$, and 24 months after injection was assessed using Kaplan-Meier analysis, as was the incidence of medication use associated with IOP elevation at each of these time points. The log-rank test was used to compare incidences in eyes with and without preexisting glaucoma. Analyses with $P<0.05$ were considered significant. Mean values are reported \pm standard deviation (SD). Cox multivariate proportional hazards regression was used to investigate the independent effects of preexisting glaucoma, age, indication for IVTA, and pseudophakia on the incidence of pressure elevation.

\section{Results}

Overall, 929 eyes of 841 patients are included in this report. Patients were $55 \%$ female of mean age $71.5 \pm 11.8$ years, and the mean follow-up time was $14 \pm 6.9$ months. The number of injections ranged from 1 to 7 per eye (Table 2), with a mean of 1.6 injections per eye. Of the entire group, 88 eyes of 76 patients had preexisting glaucoma. The minimum and maximum follow-up were 3 weeks and 37 months. The mean rate of attrition in this study was $3 \%$ per month.

\section{Incidence of Steroid-Induced Ocular Hypertension}

At 6, 12, 18, and 24 months, the cumulative Kaplan-Meier proportions of eyes with IOP measurements exceeding $21 \mathrm{mmHg}$

Table 1. Indications for Intravitreal Triamcinolone Acetonide Injection

\begin{tabular}{lrr}
\hline \multicolumn{1}{c}{ Indication } & Frequency & Percent \\
\hline Branch retinal vein occlusion & 81 & 8.8 \\
Choroidal neovascular membrane & 200 & 21.5 \\
Coats' disease & 1 & 0.1 \\
Central retinal vein occlusion & 57 & 6.1 \\
Diabetic macular edema & 415 & 44.6 \\
Eales disease & 1 & 0.1 \\
Hemiretinal vein occlusion & 16 & 1.7 \\
Hypotony & 2 & 0.2 \\
Juxtafoveal telangectasis & 3 & 0.3 \\
Macular pucker & 19 & 2.0 \\
Postoperative cystoid macular edema & 107 & 11.5 \\
Radiation retinopathy & 2 & 0.2 \\
Retinitis pigmentosa associated cystoid macular & 2 & 0.2 \\
$\quad$ edema & & \\
Uveitis & 21 & 2.3 \\
Vitreomacular traction syndrome & 2 & 0.2 \\
Total & 929 & 100 \\
\hline
\end{tabular}

Table 2. Frequency of Multiple Injections

\begin{tabular}{ccc}
\hline No. of Injections & N & Percent \\
\hline 1 & 583 & 62.8 \\
2 & 224 & 24.1 \\
3 & 71 & 7.6 \\
4 & 39 & 4.2 \\
5 & 10 & 1.1 \\
6 & 0 & 0 \\
7 & 2 & 0.2 \\
\hline
\end{tabular}

were $28.2 \%$ (95\% confidence interval [CI], 26\%-31\%), 34.6\% (95\% CI, 32\%-38\%), $41.2 \%$ (95\% CI, 38\%-46\%), and $44.6 \%$ (95\% CI, 41\%-50\%), respectively (Fig 1A) among all eyes receiving from 1 to 7 IVTA injections. Similarly, the cumulative proportions of eyes with IOP measurements $>25 \mathrm{mmHg}$ were $14.6 \%$,
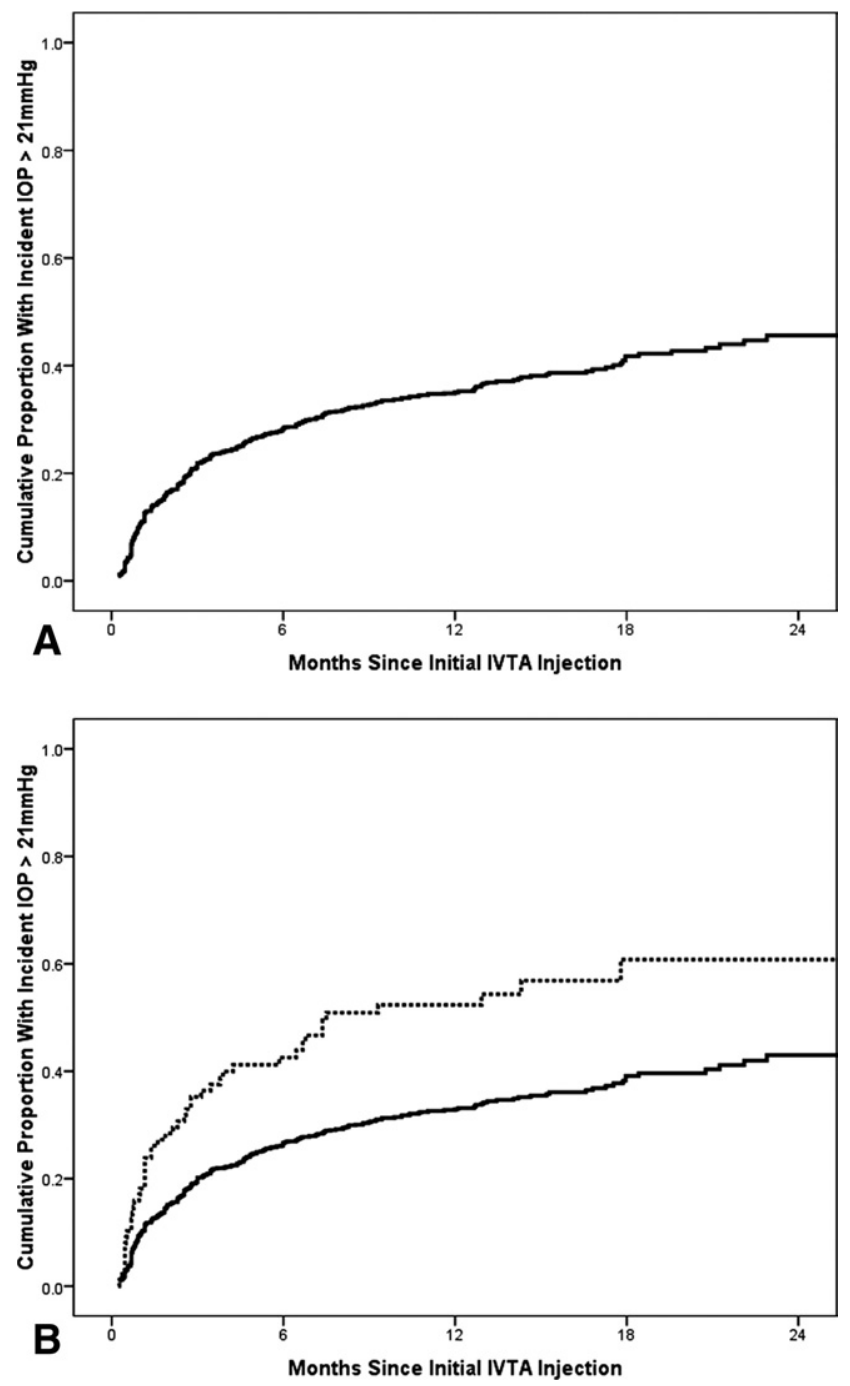

Figure 1. A, Kaplan-Meier cumulative proportion of cases with incident intraocular pressure (IOP) $>21 \mathrm{mmHg}$ by months since initial intravitreal triamcinolone acetonide (IVTA) injection for all eyes (solid line) and the subset requiring only a single IVTA (dashed line). B, Kaplan-Meier cumulative proportion of cases with incident IOP $>21 \mathrm{mmHg}$ by months since initial IVTA injection for cases with (dashed line) and without (solid line) prior history of glaucoma. 

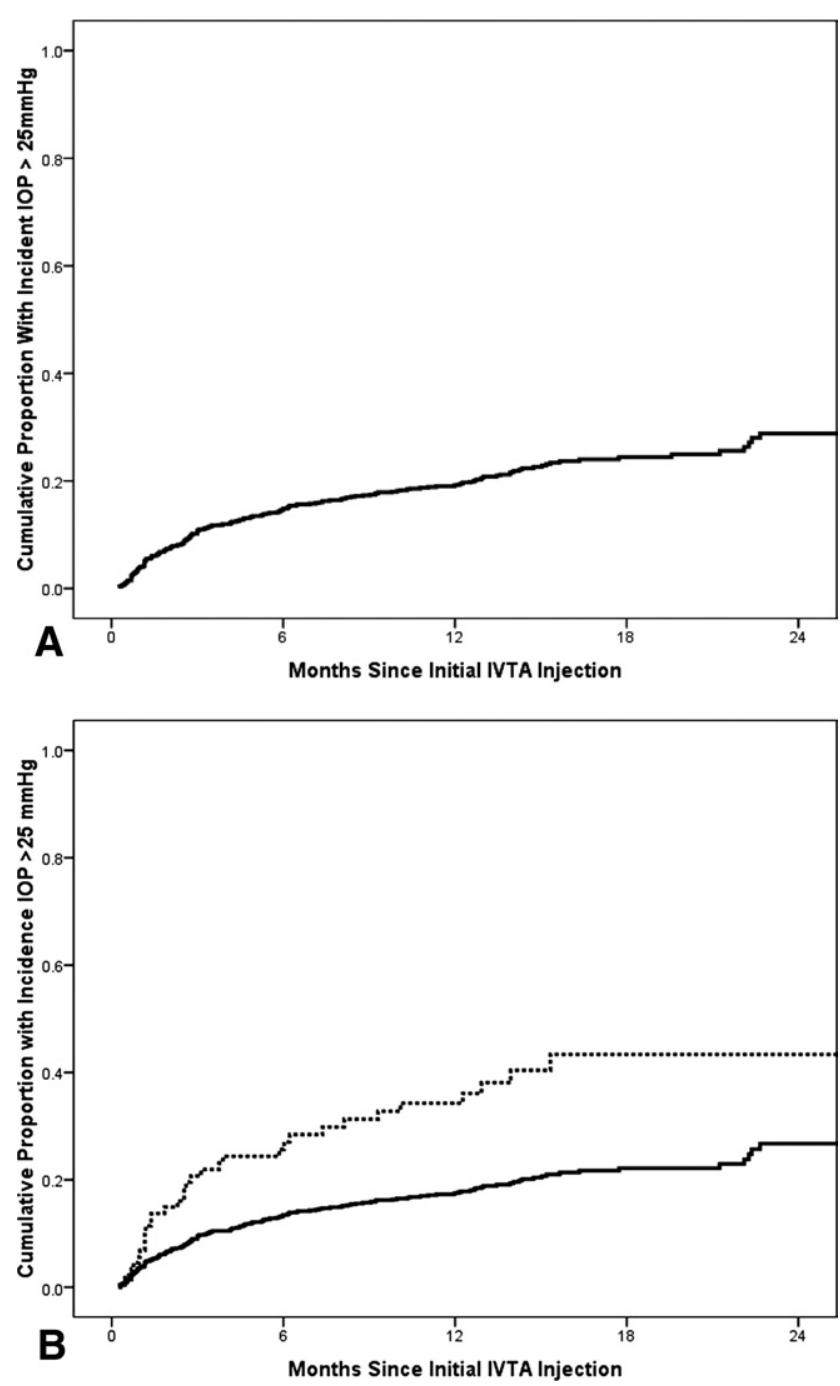

Figure 2. A, Kaplan-Meier cumulative proportion of cases with incident intraocular pressure $(\mathrm{IOP})>25 \mathrm{mmHg}$ by months since initial intravitreal triamcinolone acetonide (IVTA) injection for all eyes (solid line) and the subset requiring only a single IVTA (dashed line). B, Kaplan-Meier cumulative proportion of cases with incident IOP $>25 \mathrm{mmHg}$ by months since initial IVTA injection for cases with (dashed line) and without (solid line) prior history of glaucoma.

$19.1 \% 24.1 \%$, and $28.2 \%$, at the same time points, respectively (Fig 2A). The risk of IOP elevation was greatest between weeks 2 through 5 post-IVTA injection and decreased subsequently thereafter; however, the incidence of a first pressure elevation continued to increase throughout follow-up. Nine new cases of pressure elevation were noted at or after 1 year after a single injection. Eight of these were isolated elevations requiring no treatment, and 1 case was noted after the eye underwent a subsequent surgery.

\section{Effect of Preexisting Glaucoma and Age}

As shown in Figs 1B and 2B, eyes with preexisting glaucoma were more likely to manifest steroid-induced ocular hypertension than eyes without preexisting glaucoma (both $P<0.001$ ). Although the cumulative percentage with a pressure measurement $>21 \mathrm{mmHg}$ was substantially higher among cases with prior glaucoma than those without, for example, $52.3 \%$ (95\% CI, 41\%-63\%) versus
$32.8 \%$ (95\% CI, 30\%-36\%), respectively, at 1 year, among eyes that did experience such an elevation the average time to it was similar in the 2 groups. There was no significant difference $(P=$ 0.35 ) between the average increase in IOP at the time of the first elevation in the eyes with prior history of glaucoma (9.5 \pm 4.2$)$, and those without $(8.8 \pm 4.1)$. Among eyes with a single IVTA injection, the median time to the first IOP elevation in those with prior glaucoma was 5.0 weeks compared with 6.3 weeks for eyes without prior glaucoma $(P=0.18)$. The results for IOP measurements $>25 \mathrm{mmHg}$ were similar.

There was no persuasive evidence that cases with previous glaucoma were followed more closely than other cases. In eyes with a prior history of glaucoma the mean number of visits until the first IOP elevation was noted was $2.3 \pm 3.0$, which was more, but not significantly so $(P=0.13)$, than in the eyes without a prior history of glaucoma ( $1.7 \pm 1.5$ visits).

After accounting for prior history of glaucoma, a 10-year increase in age is associated with a $16 \%$ reduction in risk $(95 \% \mathrm{CI}$, 9\%-22\%; Cox regression) of IOP measurement $>21(P<0.001)$ and a $17 \%$ reduction in risk (95\% CI, 9\%-25\%; Cox regression) of IOP measurement $>25 \mathrm{mmHg}(P=0.001)$. Accounting for age did not reduce the significance of the effect of prior history of glaucoma $(P<0.001$ for both 21 and $25 \mathrm{mmHg})$. The effects of 2 other variables, indication for treatment and pseudophakia at the time of treatment, on the incidence of 21- and $25-\mathrm{mmHg}$ IOP elevations were also examined. After accounting for the highly significant effects of prior history of glaucoma and age, neither of these variables was statistically significant (all $P>0.10$ ).

\section{Incidence of Intraocular Pressure-Lowering Medication Use}

At $6,12,18$, and 24 months, the cumulative Kaplan-Meier proportions of eyes requiring the initiation or addition of IOP-lowing medical therapy for $13.0 \%, 16.9 \%, 20.7 \%$, and $24.2 \%$, respectively (Fig 3A). As shown in Figure 3B, the likelihood of requiring IOP-lowering therapy post-injection was similar in eyes with and without preexisting glaucoma; eyes with preexisting glaucoma, however, required medications sooner after injection than did eyes without preexisting glaucoma $(P=$ $0.002)$. Three eyes required surgical intervention for management of IOP, including 2 eyes that underwent trabeculectomy and 1 eye that underwent diode cyclophotocoagulation.

\section{Management after Intraocular Pressure Elevation}

The 130 eyes with a single IVTA injection, without prior glaucoma, and that had follow-up after a pressure measurement $>21$ $\mathrm{mmHg}$ were at risk of subsequent IOP elevation. These eyes had a median of 5 further visits over a median of 11 months follow-up. Of these, 36 (28\%) had no further IOP measurements $>21 \mathrm{mmHg}$, $82(63 \%)$ had 1 to 3 further IOP measurements $>21 \mathrm{mmHg}, 9$ (7\%) had 4 to 6 further IOP measurements $>21 \mathrm{mmHg}$, and 3 ( $2 \%$ ) had $>6$ further IOP measurements $>21 \mathrm{mmHg}$. However, many of these were pressures of $\leq 25 \mathrm{mmHg}$. Eighty-five eyes (65\%) had no further IOP measurements $>25 \mathrm{mmHg}, 43(33 \%)$ had 1 to 3 IOP measurements $>25 \mathrm{mmHg}$, and $2(2 \%)$ had $>3$ IOP measurements $>25 \mathrm{mmHg}$. Sixty-nine $(58 \%)$ of the first IOP measurements tested after the initial elevation, a median of 1 month later, were $\leq 21 \mathrm{mmHg}$.

Kaplan-Meier analysis demonstrated among eyes with $\geq 1$ IOP elevation that, by 3 months, a cumulative proportion of $12.3 \%$ had subsequent IVTA injections. This increased to $22.3 \%$ at 6 months and $34.1 \%$ at 1 year. There was no significant difference between the rates of post-IOP elevation IVTA injections between subjects with and without prior glaucoma $(P=0.66$; log-rank test $)$. 

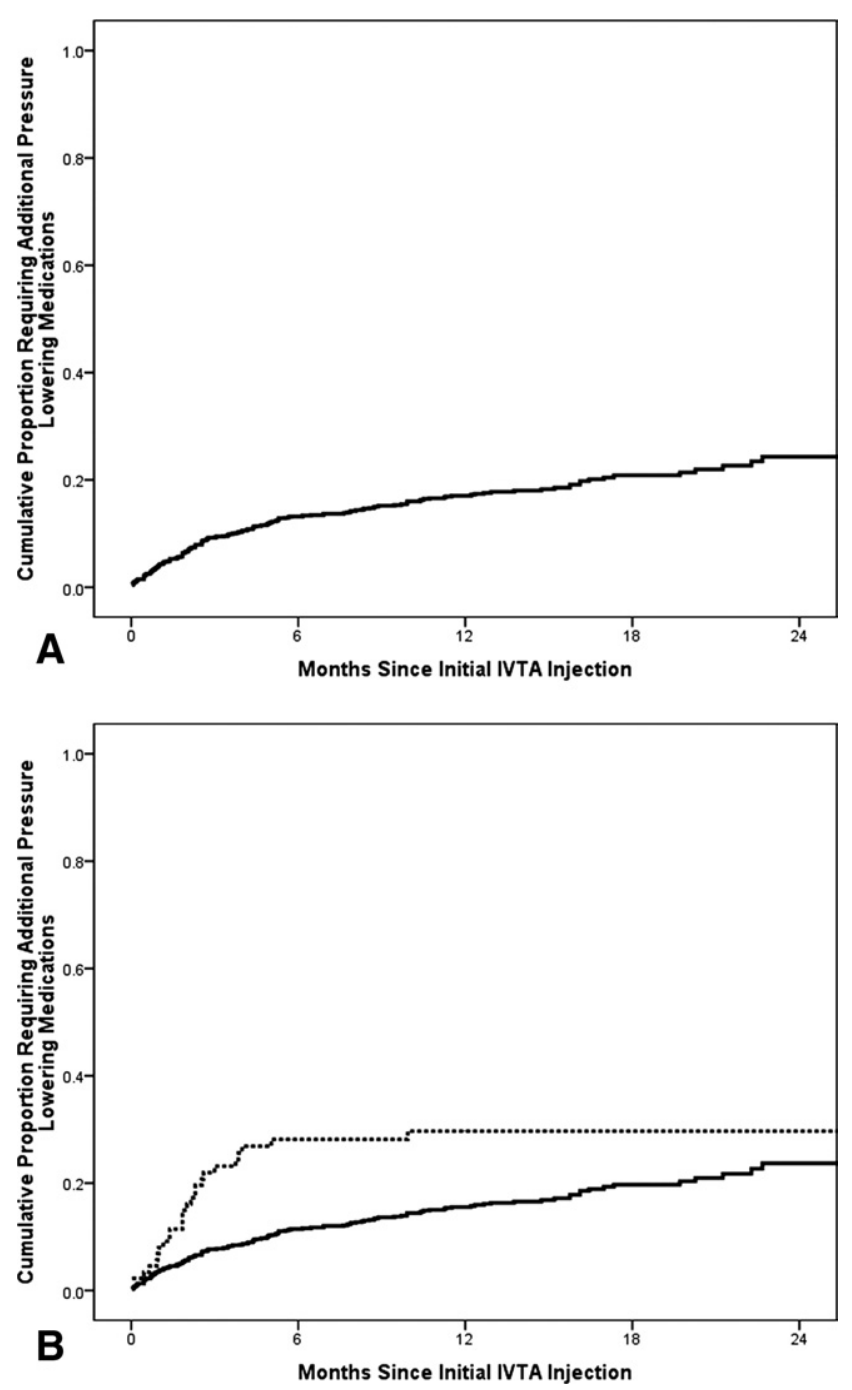

Figure 3. A, Kaplan-Meier cumulative proportion of cases requiring additional pressure lowering medications by months since initial intravitreal triamcinolone acetonide (IVTA) injection for all eyes. B, Kaplan-Meier cumulative proportion of cases requiring additional pressure-lowering medications by months since initial IVTA injection for cases with (dashed line) and without (solid line) prior history of glaucoma.

\section{Risk with Multiple Injections}

After the initial injection, 250 of 929 eyes (26.9\%) experienced an IOP measurement $>21 \mathrm{mmHg}$ before the first re-injection or loss to follow-up; approximately half of these (134 [14.4\%]) experienced an IOP measurement exceeding $25 \mathrm{mmHg}$ (Table 3). The incidence of IOP elevation rose slightly after the second and third injections but decreased after a fourth injection; but these small differences in incidence rates may be due to a diminishing sample size.

Using Cox survival regression while excluding cases with prior glaucoma, the risk of a $>21-\mathrm{mmHg}$ elevation in pressure after the second IVTA injection is 3.4 (95\% CI, 2.2-5.2) times higher in eyes with an elevation before the second injection (i.e., after the first injection). The risk of a $>21-\mathrm{mmHg}$ pressure elevation after the third IVTA injection is $3.9(95 \% \mathrm{CI}, 1.8-8.4)$ times higher in eyes with an elevation before the third injection (i.e., after either the first or second injections or both). The risk of a $>21-\mathrm{mmHg}$ pressure elevation after the fourth IVTA injection is 2.2 (95\% CI,
0.6-8.6) times higher than in eyes with an elevation before the fourth injection. Similarly, the risk of a $>25-\mathrm{mmHg}$ pressure elevation after second or third IVTA injections was 5.5 (95\% CI, 2.9-10.4) and 2.9 (95\% CI, 0.9-9.3) times higher, respectively, in eyes with than without an IOP elevation on a prior injection; too few IOP measurements $>25 \mathrm{mmHg}$ occurred after fourth injections to permit analysis.

\section{Discussion}

This study demonstrates that IOP measurements of $>21$ mmHg after IVTA therapy are common, and although many eyes with IOP elevation required medical therapy to manage IOP, surgical intervention for IOP control was rarely necessary.

In our series, $45.6 \%$ of eyes experienced an IOP measurement of $>21 \mathrm{mmHg}$ within 2 years after IVTA therapy; only $28.9 \%$ experienced an IOP measurement of $>25$ $\mathrm{mmHg}$. These rates compare favorably with other reports. In a series of 89 eyes receiving $\geq 1$ injections of $4 \mathrm{mg}$ IVTA, Smithen et $\mathrm{al}^{10}$ reported a $40.4 \%$ incidence of IOP elevation to $\geq 24 \mathrm{mmHg}$ over a mean follow-up period of 9.3 months. A meta-analysis of 305 eyes receiving a single 20-mg IVTA injection conducted by Jonas et $\mathrm{al}^{11}$ reported that $41.2 \%$ of eyes experienced an IOP elevation $>21 \mathrm{mmHg}$ over a mean follow-up period of 10.4 months.

Subjects in our study received up to 7 IVTA injections at the discretion of the treating physician throughout their course of therapy. These real-world data reflect the fact that many patients require $>1$ IVTA injection for long-term disease management. Interestingly, the overall incidence of IOP elevation did not increase significantly with multiple injections. One explanation for this may be the reluctance to re-inject an eye that previously manifested a significant IOP elevation after a prior injection. It is the investigator's practice to repeat injections, if indicated, even in eyes that have previously exhibited an IOP elevation, unless the prior IOP elevation was extremely high or recalcitrant to treatment. Alternatively, the progressively higher rate of IOP elevation with successive injections described in Table 3 may be a result of the diminishing sample size receiving greater numbers of injections; this is supported by the significant overlap in the $95 \%$ confidence intervals for IOP elevation rates after successive injections. This observation that IOP elevation rates are relatively independent of the number of injections given is supported by the reports by Smithen et $\mathrm{al}^{10}$ and Shukla et al. ${ }^{11}$ Jonas et $\mathrm{al}^{12}$ reported eyes receiving a single injection, while $36 \%$ of eyes in the series by Smithen et al ${ }^{10}$ received multiple injections (compared with $37 \%$ in our series). Yet the incidence of IOP elevation was remarkably similar in these 3 series: $41.2 \%$ in Jonas' single-injection series ${ }^{11}$ versus $40.4 \%$ and $45.6 \%$ in Smithen et al ${ }^{10}$ and our multi-injection series, respectively.

Our analysis indicates that eyes are at maximum risk of an IOP elevation from weeks 2 through 5 after IVTA. To further assess the timing of IOP elevation, we examined eyes receiving only a single injection and found that, although the onset of pressure increases for most cases occurred within 6 weeks, new-onset IOP elevation was noted many months after the IVTA injection. These were fre- 


\section{Roth et al · Long-Term Incidence IOP after IVTA}

Table 3. Incidence of Intraocular Pressure (IOP) Elevation $>21 \mathrm{mmHg}$ and $>25 \mathrm{mmHg}$ after Each Intravitreal Triamcinolone (IVTA) Injection

\begin{tabular}{|c|c|c|c|c|c|c|c|c|}
\hline \multirow{2}{*}{$\begin{array}{l}\text { No. of } \\
\text { Injections }\end{array}$} & \multirow[b]{2}{*}{ Total (n) } & \multirow{2}{*}{$\begin{array}{l}\text { Mean Follow-up } \\
\text { (SD), mos }\end{array}$} & \multicolumn{3}{|c|}{ IOP Spike $>21 \mathrm{mmHg}$} & \multicolumn{3}{|c|}{ IOP Spike $>25 \mathrm{mmHg}$} \\
\hline & & & $n$ & $\%$ & $95 \% \mathrm{CI}$ & $n$ & $\%$ & $95 \% \mathrm{CI}$ \\
\hline 1 & 929 & $10.3(6.5)$ & 250 & 26.9 & $24.1-29.9$ & 134 & 14.4 & $12.2-16.9$ \\
\hline 2 & 346 & $7.5(5.2)$ & 120 & 34.7 & $29.7-40.0$ & 63 & 18.2 & $14.3-22.7$ \\
\hline 3 & 122 & $6.2(4.8)$ & 52 & 42.6 & $33.7-51.9$ & 23 & 18.9 & $12.3-26.9$ \\
\hline 4 & 51 & $3.9(3.4)$ & 16 & 31.4 & $19.1-45.9$ & 4 & 7.8 & $2.2-18.9$ \\
\hline 5 & 12 & $5.9(4.9)$ & 3 & 25.0 & $5.5-57.2$ & 1 & 8.3 & $0.2-38.5$ \\
\hline 6 & 2 & $3.7(0.05)$ & 0 & 0 & $0.0-84.2$ & 0 & 0 & $0.0-84.2$ \\
\hline 7 & 2 & $1.4(1.3)$ & 1 & 50.0 & $1.3-98.7$ & 0 & 0 & $0.0-84.2$ \\
\hline
\end{tabular}

$\mathrm{CI}=$ confidence interval; $\mathrm{SD}=$ standard deviation.

quently isolated and did not require treatment. Our series, lacking a comparison control group, cannot establish the etiology of these very late-onset pressure increases.

Eyes experiencing an IOP elevation after IVTA therapy were significantly more likely to rise again on re-injection than eyes that did not develop an IOP elevation with prior injections. Eyes with IOP elevation after the first injection were 3.4 times more likely to rise on a subsequent injection than eyes that did not rise after the first injection. Similarly, an IOP elevation after the first or second injection (or both) increased the risk of IOP elevation after the third injection by 3.9-fold. When re-injecting an eye with a history of IOP elevation after previous IVTA injections, clinicians are advised to monitor carefully for subsequent IOP elevation.

Preexisting glaucoma also increased the risk of experiencing an IOP elevation after IVTA therapy, as did younger age, a finding previously reported by Shukla et al. ${ }^{12}$ Eyes with preexisting glaucoma experienced IOP elevation more commonly and more quickly than nonglaucomatous eyes. Given that these eyes are likely to be more susceptible to IOP-related optic nerve damage, IVTA therapy should be used with caution in glaucomatous eyes, and careful follow-up is necessary to identify steroid-related IOP elevation early and institute appropriate IOP-lowering interventions promptly.

Elevation of the IOP in our study was easily managed with IOP-lowering medications. The incidences of IOP medication use at various time points closely resembles the incidence of IOP elevation $>25 \mathrm{mmHg}$ at corresponding time points. This is consistent with the common clinical practice of observing modest IOP elevations without treatment, and treating IOP measurements of $>25 \mathrm{mmHg}$. Interestingly, only 3 eyes in our series required surgical intervention for IOP control (3/929; [0.3\%]). This is comparable to the report by Jonas et al, ${ }^{11}$ in which 3 of 305 $(1 \%)$ of eyes required incisional surgery for IOP control.

In conclusion, IVTA is a common therapy for a variety of posterior segment conditions. Steroid-induced ocular hypertension is a well-known complication of IVTA therapy. This report describes the incidence and severity of IOP elevation in a large cohort of eyes undergoing a variable course of IVTA injections, ranging from 1 to 7 injections. Elevated IOP is common after IVTA therapy, and eyes with preexisting glaucoma, as well as those with a history of an IOP elevation after a prior IVTA injection are at increased risk of steroid-induced ocular hypertension and should be followed more closely after any IVTA injection. Elevations in IOP were generally mild to moderate in magnitude and easily controlled with medical IOP-lowering therapy. When managed appropriately, the risk of steroid-induced ocular hypertension should not be an absolute barrier to offering IVTA therapy in appropriate patients.

\section{References}

1. Becker B, Mills DW. Elevated intraocular pressure following corticosteroid eye drops. JAMA 1963;185:884-6.

2. Armaly MF. Effect of corticosteroids on intraocular pressure and fluid dynamics. I. The effect of dexamethasone in the normal eye. Arch Ophthalmol 1963;70:482-91.

3. Armaly MF. Effect of corticosteroids on intraocular pressure and fluid dynamics. II. The effect of dexamethasone in the glaucomatous eye. Arch Ophthalmol 1963;70:492-9.

4. Jones R III, Rhee DJ. Corticosteroid-induced ocular hypertension and glaucoma: a brief review and update of the literature. Curr Opin Ophthalmol 2006;17:163-7.

5. Ricci F, Missiroli F, Parravano M. Argon laser trabeculoplasty in triamcinolone acetonide induced ocular hypertension refractory to maximal medical treatment. Eur J Ophthalmol 2006;16:756-7.

6. Pizzimenti JJ, Nickerson MM, Pizzimenti CE, Kasten-Aker AG. Selective laser trabeculoplasty for intraocular pressure elevation after intravitreal triamcinolone acetonide injection. Optom Vis Sci 2006;83:421-5.

7. Viola F, Morescalchi F, Staurenghi G. Argon laser trabeculoplasty for intractable glaucoma following intravitreal triamcinolone. Arch Ophthalmol 2006;124:133-4.

8. Jonas JB. Intravitreal triamcinolone acetonide: a change in a paradigm. Ophthalmic Res 2006;38:218-45.

9. Roth DB, Realini T, Feuer WJ, et al. Short-term complications of intravitreal triamcinolone acetonide. Retina 2008;28:66-70.

10. Smithen LM, Ober MD, Maranan L, Spaide RF. Intravitreal triamcinolone acetonide and intraocular pressure. Am J Ophthalmol 2004;138:740-3.

11. Jonas JB, Degenring RF, Kreissig I, et al. Intraocular pressure elevation after intravitreal triamcinolone acetonide injection. Ophthalmology 2005;112:593-8.

12. Shukla D, Vidhya N, Prasad NM, et al. Evaluation of patient age as a risk factor for intraocular pressure elevation after intravitreal triamcinolone. Am J Ophthalmol 2007;144:453-4. 


\section{Footnotes and Financial Disclosures}

Originally received: January 21, 2008.

Final revision: October 3, 2008.

Accepted: October 6, 2008.

Available online: January 20, 2009.

${ }^{1}$ Robert Wood Johnson Medical School, New Brunswick, New Jersey.

${ }^{2}$ West Virginia University Eye Institute, Morgantown, West Virginia.

${ }^{3}$ University of Miami School of Medicine, Miami, Florida.

${ }^{4}$ UMDNJ-New Jersey Medical School, Newark, New Jersey.
Presented at: the American Academy of Ophthalmology Annual Meeting November, 2007.

Financial Disclosure(s):

The authors have no proprietary or commercial interest in any materials discussed in this article.

Correspondence:

Daniel B. Roth, MD, Assistant Professor, Robert Wood Johnson School of Medicine, Retina Vitreous Center, 125 Paterson Street, New Brunswick, NJ 08701. E-mail: rothretina@gmail.com. 